\title{
Saccharomyces cerevisiae-Derived HBsAg Preparations Differ in Their Attachment to Monocytes, Immune-Suppressive Potential, and T-Cell Immunogenicity
}

\author{
Peter Vanlandschoot, ${ }^{1 *}$ Freya Van Houtte, ${ }^{1}$ Frans Hoek, ${ }^{2}$ Rienk Nieuwland, ${ }^{2}$ and Geert Leroux-Roels ${ }^{1}$ \\ ${ }^{1}$ Center for Vaccinology, Department of Clinical Biology, Microbiology and Immunology, Ghent University Hospital, \\ Ghent, Belgium \\ ${ }^{2}$ Department of Clinical Chemistry, Academic Medical Center, Amsterdam, The Netherlands
}

Expression of the hepatitis $\mathrm{B}$ virus $\mathrm{S}$ protein results in the formation of a lipoprotein particle, the hepatitis B surface antigen (HBsAg). Such particles, produced in Saccharomyces cerevisiae, bind to the cell surface of monocytes through interaction with the lipopolysaccharide binding protein and the lipopolysaccharide receptor, CD14. This attachment is suggested to depend on the presence of charged phospholipids in the particles. In addition, such particles interfere with the lipopolysaccharide and interleukin-2induced activation of monocytes. In the present study, it is reported that of three Saccharomyces cerevisiae-derived HBsAg preparations, two have a reduced capacity to bind to monocytes. A correlation with a reduced potential to inhibit the lipopolysaccharide-induced activation of monocytes and an increased potential to stimulate HBsAg-specific T-cell proliferation is observed. Surprisingly, differences in phospholipid content that might explain these observations, were not detected. J. Med. Virol. 70:513-519, 2003. (๑) 2003 Wiley-Liss, Inc.

KEY WORDS: rHBsAg; CD14; lipopolysaccharide binding protein; phospholipid; lipopolysaccharide

\section{INTRODUCTION}

Hepatitis B virus (HBV)-infected hepatocytes produce and secrete noninfectious particles, hepatitis B surface antigen ( $\mathrm{HBsAg})$. HBsAg consists mainly of spherical particles of 22-nm diameter and a small number of filamentous particles. These particles can accumulate to several $100 \mu \mathrm{g} / \mathrm{ml}$ in the circulation. The spherical particles contain viral-encoded membrane proteins and approximately $30 \%$ (by weight) of host cell-derived lipids. The S protein accounts for more than $90 \%$ of the protein contained in $\mathrm{HBsAg}$. The $\mathrm{L}$ and $\mathrm{M}$ proteins form the remainder. These three proteins share $226 \mathrm{C}$ terminal amino acids. Both glycosylated and nonglycosylated forms of these viral membrane proteins are present in the particles [Seeger and Mason, 2000]. In 1981, a plasma-derived HBsAg vaccine was licensed in the United States. Plasma-derived HBsAg in the vaccine was soon replaced by recombinant $\mathrm{HBsAg}$, produced in Saccharomyces cerevisiae. More recently, HBsAg produced in other yeasts (Hansenula polymorpha and Pichia pastoris) and mammalian cells is also being used. In contrast to the plasma and mammalian cellderived $\mathrm{HBsAg}$, the different yeast-derived $\mathrm{HBsAg}$ particles contain only the nonglycosylated S-protein. Despite these differences in protein content and protein modifications, it is generally accepted that, both structurally and antigenically, the yeast-derived $\mathrm{HBsAg}$ closely resembles the natural and mammalian cellderived HBsAg.

Recently, it was shown that $S$. cerevisiae-expressed $\mathrm{HBsAg}$ (rHBsAg) suppressed the lipopolysaccharide (LPS) and interleukin-2 (IL-2)-induced production of proinflammatory cytokines, while upregulating the LPS-induced expression of the anti-inflammatory IL10 by human monocytes [Vanlandschoot et al., 2002a,c] . Moreover, the preferential binding of rHBsAg to the monocytes of peripheral blood mononuclear cells (PBMCs) was observed [Vanlandschoot et al., 2002a]. The LPS receptor (CD14) was shown to be necessary for the attachment of rHBsAg to occur. A serum protein that enhanced the binding of rHBsAg to monocytes was

*Correspondence to: Peter Vanlandschoot, Center for Vaccinology, Department of Clinical Biology, Microbiology and Immunology, Ghent University Hospital, De Pintelaan 185, 9000 Ghent, Belgium. E-mail: peter.vanlandschoot@rug.ac.be

Accepted 20 February 2003

DOI 10.1002/jmv.10425

Published online in Wiley InterScience

(www.interscience.wiley.com) 
identified as the lipopolysaccharide binding protein (LBP) [Vanlandschoot et al., 2002b]. Surprisingly, it was found that HBsAg, purified from plasma (pHBsAg), was not endowed with this property of binding in a LBPdependent manner to the surface of CD14-expressing cells. Experimental evidence was presented that charged phospholipids, not or no longer present in $\mathrm{pHBsAg}$, were responsible for the interaction of $\mathrm{rHBsAg}$ with the (cellular) receptors [Vanlandschoot et al., $2002 \mathrm{~b}$. Because of this difference between pHBsAg and $\mathrm{rHBsAg}$, it was considered important to investigate whether HBsAg expressed in other yeasts or mammalian cells, might show differences in attachment to monocytes, and their capacity to interfere with the LPS-induced activation of monocytes. Several vaccine producers of $\mathrm{HBsAg}$ were contacted, but none was willing to supply HBsAg. The study was therefore limited to the use of three different lots of $S$. cerevisiaeexpressed rHBsAg, obtained form GlaxoSmithKline. Nevertheless, clear differences in binding, immune suppression, and T-cell immunogenicity were observed among these preparations.

\section{MATERIALS AND METHODS rHBsAg}

Three rHBsAg (subtype $\mathrm{adw}_{2}$ ) preparations produced in $S$. cerevisiae were kindly provided by GlaxoSmithKline Biologicals (Rixensart, Belgium). DVP93/1 (1,000 $\mu \mathrm{g} /$ $\mathrm{ml}$ ) were produced and purified in 1993, and HEF002 $(1,096 \mu \mathrm{g} / \mathrm{ml})$ and HEP715 $(1562 \mu \mathrm{g} / \mathrm{ml})$ in 2000 . These rHBsAg particles were dissolved in phosphate-buffered saline (PBS); no adjuvant or preservatives were added. The purity of the rHBsAg preparations was judged by high-performance liquid chromatography (HPLC) analysis, as well as by sodium dodecyl sulfate-polyacrylamide gel electrophoresis (SDS-PAGE) with Coomassie staining and is $>98 \%$. rHBsAg is composed of welldefined subviral particles, which contain only the nonglycosylated S protein. Similar preparations are used worldwide as human $\mathrm{HBV}$ vaccines after adsorption on to aluminum hydroxide.

rHBsAg (DVP93/1) was biotinylated using an enhanced chemiluminescence system (ECL) protein biotinylation module (RPN 2202, Amersham Pharmacia Biotech) as described by Vanlandschoot et al. [2002a]. Biotinylated rHBsAg (b-rHBsAg) was purified by gel filtration on a Sephadex G25 column using PBS; 1-ml fractions were collected, and the two b-rHBsAg peak fractions were pooled.

\section{Enzyme-Linked Immunosorbent Assay}

Maxisorb 96-well plates (Nunc, Roskilde, Denmark) were coated with $\mathrm{rHB}$ sAg or b-rHBsAg in PBS. The wells were blocked with $0.1 \%$ bovine serum albumin (BSA) in PBS, followed by three washings (PBS, 0.1\% Triton $\mathrm{X}-100$ ). HBsAg-specific monoclonal antibodies (MAb; $1 \mu \mathrm{g} / \mathrm{ml}$ ) or horseradish peroxidase (HPO)-labeled streptavidin (SAPE) were added, and the plates were incubated for $1 \mathrm{hr}$ at room temperature. Antibodies were detected with peroxidase-labeled goat-anti-human antibodies (Sigma). After three washings, 3.3',5,5'tetramethylbenzidine (Sigma) was added. After $30 \mathrm{~min}$, the reaction was stopped with $1 \mathrm{~N} \mathrm{H}_{2} \mathrm{SO}_{4}$.

\section{Antibodies}

Human anti-HBsAg MAb F47B was a kind gift from Lia Sillekens (Centraal Laboratorium van de Bloedbank, Amsterdam). The human anti-a MAb, which recognizes the "a" determinant of $\mathrm{HBsAg}$, was developed in the laboratory and biotinylated as described above for rHBsAg. For fluorescence-activated cell sorting (FACS) analysis, human antibodies were detected with rabbit anti-human F(ab')2-FITC. Phycoerythrin-labeled streptavidin (Strep-PE) was obtained from Becton Dickinson.

\section{LPS Binding Protein}

LBP was expressed in Chinese hamster ovary (CHO) cells and was purified as described [Stelter et al., 1999].

\section{Cells}

Human peripheral blood mononuclear cells (PBMCs) were isolated from buffy coats, using Ficoll-Hypaque centrifugation (density $=1.077 \mathrm{~g} / \mathrm{ml}$; Nycomed Pharma, Oslo, Norway). Cells were stored in liquid nitrogen. THP-1 cells were grown in cRPMI (RPMI 1640-10\% fetal cell serum [FCS], $2 \mathrm{mM}$ L-glutamine, $1 \mathrm{mM} \mathrm{Na-}$ pyruvate, $50 \mathrm{U} / \mathrm{ml}$ penicillin, $50 \mu \mathrm{g} / \mathrm{ml}$ streptomycin, $20 \mu \mathrm{M} \beta$-mercaptoethanol). To induce differentiation, $100 \mathrm{nM}$ 1,25-dihydroxy vitamin D3 (Calbiochem) was added for $24 \mathrm{hr}$. CHO cells that express human CD14 and $\mathrm{CHO}$ cells transfected with the empty vector only [Jack et al., 1995; Stelter et al., 1997] were grown in MEM- $\alpha$ without nucleosides and ribonucleosides (Gibco-BRL) supplemented with 10\% FCS, $2 \mathrm{mM} \mathrm{L-}$ glutamine, $50 \mathrm{U} / \mathrm{ml}$ penicillin, $50 \mu \mathrm{g} / \mathrm{ml}$ streptomycin, $100 \mathrm{nM}$ (plasmid-transfected CHO cells), or $500 \mathrm{nM}$ methotrexate (CHO cells that express CD14). Cultured cells were detached mechanically or with nonenzymatic cell dissociation buffer (Sigma), washed twice with $2 \%$ human $\mathrm{AB}$ serum (Bio-Whitaker) in Hank's balanced salt solution (HBSS; Gibco-BRL) (2\% HS-HBSS), and stained as described below.

\section{Staining of Cells}

PBMCs were thawed and washed twice with $2 \%$ HSHBSS; $10^{6}$ cells were incubated with b-rHBsAg or rHBsAg in $200 \mu \mathrm{l} \mathrm{HBSS}$ for 90 min on ice. During this incubation, $2 \% \mathrm{HS}$ or $0.5 \mu \mathrm{g} / \mathrm{ml} \mathrm{LBP}$ was added as indicated. Human serum used in these binding assays was not heat-inactivated. After two washings with the same solution, cells were incubated with Strep-PE or HBsAgspecific antibodies, followed by FITC-labeled antibodies in $2 \% \mathrm{HS}-\mathrm{HBSS}$ for $1 \mathrm{hr}$ on ice. After two washings, cells were resuspended in $1 \mathrm{ml} 2 \%$ HS-HBSS or PBS, containing propidium iodide (PI). Cells were analyzed on a FACScan flow cytometer (Becton Dickinson). Dead cells, 
which incorporated PI, were gated out of analysis. At least 5,000 cells were counted per analysis. Fluorescence (530 nm for FITC and $580 \mathrm{~nm}$ for PE) was measured. Median fluorescence was determined in each case. The signals were acquired in a logarithmic mode for FL1 (FITC) and FL2 (PE). Threshold levels were set according to negative (Strep-PE only) and isotypic controls.

\section{LPS Treatment of THP-1}

In this study, $3.10^{5}$ THP-1 cells were treated for $24 \mathrm{hr}$ with $100 \mathrm{nM}$ 1,25-dihydroxy vitamin D3. After washing, the cells were incubated in cRPMI with or without $10 \mathrm{ng} / \mathrm{ml}$ LPS (Escherichia coli 0111:B4, Sigma); $0,1,10,25$, or $50 \mu \mathrm{g} / \mathrm{ml} \mathrm{rHBsAg}$ was added. Cell supernatants were collected after $4 \mathrm{hr}$ and were tested for the presence of tumor necrosis factor- $\alpha$ (TNF- $\alpha)$.

\section{Cytokine Determinations}

The concentration of TNF- $\alpha$ in cell supernatant was determined using commercially available kits (Biosource) according to the manufacturer's instructions.

\section{Lymphoproliferation Assay}

Unfractionated PBMCs were suspended in RPMI 1640 medium supplemented with $25 \mathrm{mM}$ Hepes, $50 \mathrm{U} /$ $\mathrm{ml}$ penicillin, $50 \mu \mathrm{g} / \mathrm{ml}$ streptomycin, $2 \mathrm{mM}$ L-glutamin, $5 \times 10^{-5} \mathrm{M} \beta$-mercaptoethanol, and $10 \%$ heat-inactivated human $\mathrm{AB}$ serum. PBMCs $\left(2 \times 10^{5} /\right.$ well $)$ from vaccinated or $\mathrm{HBV}$-infected subjects were cultured for 6 days $\left(37^{\circ} \mathrm{C}\right.$ in $\left.5 \% \mathrm{CO}_{2}\right)$ in 96 -well round-bottomed microtiter plates containing $\mathrm{rHBsAg}$ particles at the concentrations indicated. All assays were carried out in triplicate, and ${ }^{3} \mathrm{H}-\mathrm{TdR}(0.5 \mu \mathrm{Ci} /$ well, Amersham Inter- national, UK) was added $18 \mathrm{hr}$ before termination. Cultures were harvested using an automated harvesting device and were assayed for ${ }^{3} \mathrm{H}$-TdR incorporation by liquid scintillation counting in an LKB-Wallac 8100 Counter.

\section{Phospholipid Extraction, Determination, and Quantification}

Phospholipids were extracted according to a modified Bligh and Dyer method [Bligh and Dyer, 1959; Weerheim et al., 2002]. Phospholipids were determined and quantified by high-performance thin-layer chromatography (HPTLC) as described [Weerheim et al., 2002].

\section{RESULTS}

\section{Reduced Attachment of HEF002 and HEP715 to CD14 ${ }^{+}$Cells}

Two different methods were used to compare the binding capacities of the three $\mathrm{rHBsAg}$ preparations. The first assay was based on the antibody-mediated detection of rHBsAg bound to the surface of $\mathrm{CHO}$ cells that express CD14. However, this method requires that the different particles show a similar reactivity toward the antibody used. Using two different human MAbs (anti-a and F47B) the antigenic quality of the three preparations was shown to be similar (Fig. 1). More importantly, the results demonstrated that antibody F47B could be used to compare the binding of these rHBsAg preparations to the cell surface. The second assay was based on the capacity of nonbiotinylated rHBsAg to compete with the binding of biotinylated rHBsAg, derived from DVP93/1, to monocytes of PBMCs.
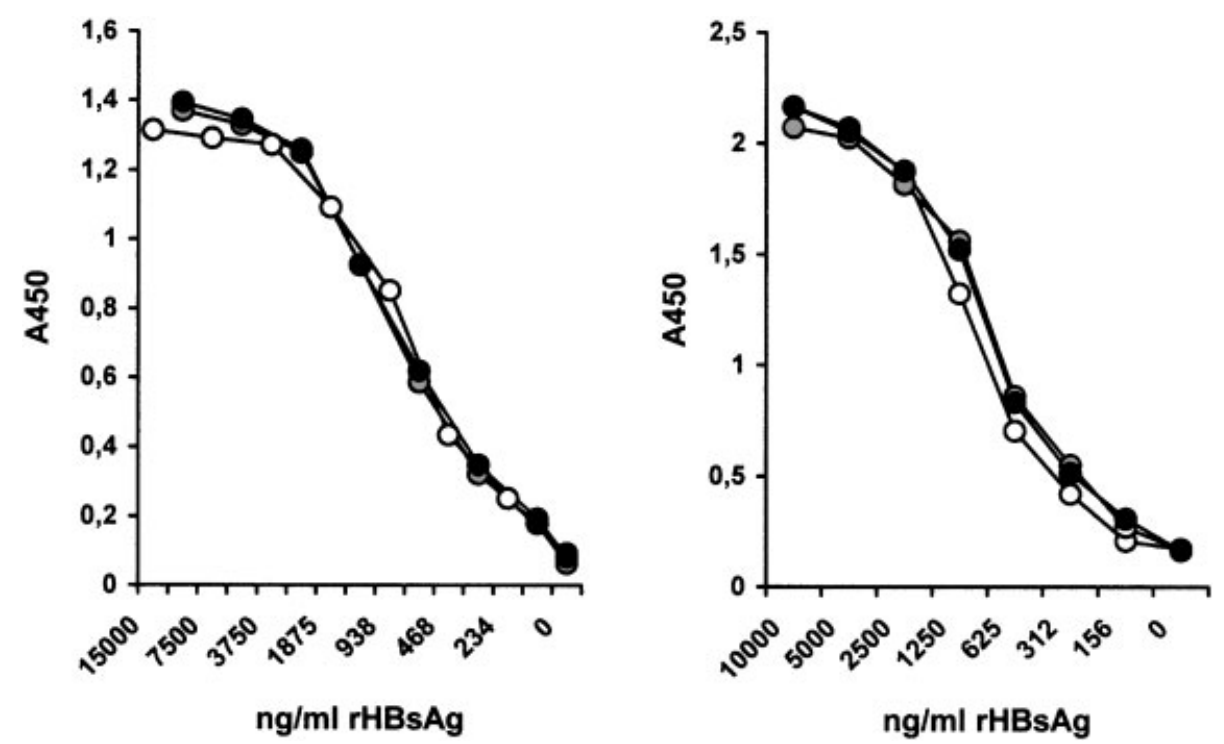

Fig. 1. Antigenic structure of DVP93/1, HEF002, and HEP715 is very similar. Enzyme-linked immunosorbent assay (ELISA) plates were coated with DVP93/1 (black circles), HEF002 (gray circles), and HEP715 (white circles). After blocking with bovine serum albumin (BSA), human monoclonal antibodies (MAbs) F47B (left) and anti-a (right) were allowed to bind to the particles. MAbs were detected with goat-anti human peroxidase-labeled antibodies. 
$\mathrm{CHO}$ cells that expressed CD14 were incubated on ice with $2 \mu \mathrm{g} / \mathrm{ml} \mathrm{rHBsAg}$ and $0.5 \mu \mathrm{g} / \mathrm{ml} \mathrm{LBP}$ in HBSS. Bound rHBsAg was detected using antibody F47B and rabbit anti-human F( $\left.\mathrm{ab}^{\prime}\right)$ 2-FITC. As shown in Figure 2, attachment of HEF002 en HEP715 to the cell surface was five to six times lower as compared with the attachment of DVP93/1.

As shown in Figure 3, the use of $5 \mu \mathrm{g} / \mathrm{ml}$ of nonbiotinylated DVP93/1 led to a reduction in binding of biotinylated DVP93/1 by more then $50 \%$. A similar reduction required the use of $\sim 50 \mu \mathrm{g} / \mathrm{ml} \mathrm{HEF002} \mathrm{and}$ HEP715. Taken together, these results demonstrated clearly the reduced capacity of these two rHBsAg preparations to bind to the cell surface of CD14-expressing cells.

\section{HEF002 and HEP715 have a Reduced Capacity to Inhibit LPS-Induced Activation of THP-1 Cells}

Previously, it was demonstrated that the coadministration of LPS and rHBsAg to monocytes or THP-1 cells led to a substantial inhibition in LPS-induced TNF- $\alpha$ secretion [Vanlandschoot et al., 2002a,c]. To determine whether the reduced binding of HEF002 and HEP715 to $\mathrm{CD}_{14}{ }^{+}$cells, correlated with a reduced inhibition of LPS-induced activation of monocytes, the THP-1 assay was used. Because THP-1 cells do not express CD14, cells were first treated with $100 \mathrm{nM}$ 1,25-dihydroxy vitamin D3. Differentiated THP-1 cells were incubated with LPS in the presence of different concentrations of $\mathrm{rHBsAg}$. Culture supernatant was collected after $4 \mathrm{hr}$ of stimulation and tested for the presence of TNF- $\alpha$. At this

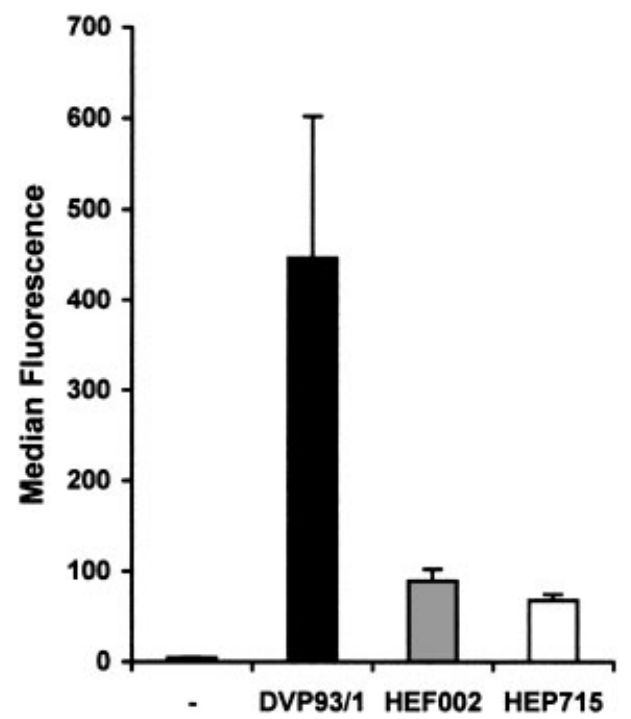

Fig. 2. Reduced attachment of HEF002 and HEP715 to Chinese hamster ovary (CHO)-CD14. CHO-CD14 cells were incubated for $90 \mathrm{~min}$ on ice with $2 \mu \mathrm{g} / \mathrm{ml}$ of the different preparations together with $0.5 \mu \mathrm{g} / \mathrm{ml}$ lipopolysaccharide binding protein (LBP) in Hank's balanced salt solution (HBSS). Particles were detected using monoclonal antibody (MAb) F47B. Median fluorescence was determined. The data represent the mean of three separate experiments. Error bars represent SD.

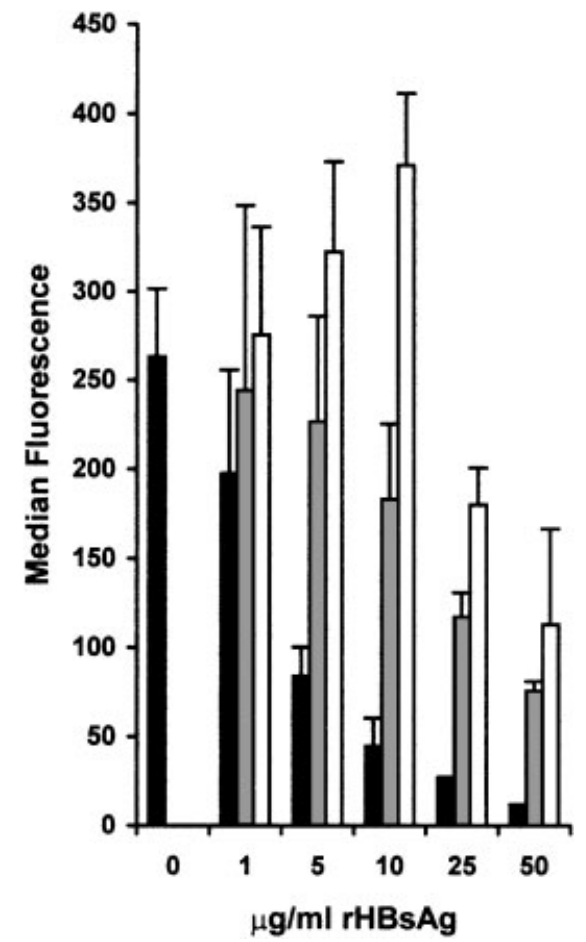

Fig. 3. Reduced inhibition of biotinylated $S$. cerevisiae-expressed hepatitis B surface antigen (b-rHBsAg) binding to monocytes by nonbiotinylated HEF002 and HEP715. Peripheral blood mononuclear cells (PBMCs) were incubated with different amounts of DVP93/1 (black bars), HEF002 (gray bars), and HEP715 (white bars) in $200 \mu 11 \%$ HS-Hank's balanced salt solution (HBSS). After 90 min, b-rHBsAg was added and the cells were incubated for another hour. After two washes, cells were stained with Strep-PE. Median fluorescence was determined. The data represent the mean of three separate experiments. Error bars represent SD. The bar on the left represents binding of b-rHBsAg.

4-hr time point, secretion has reached its maximum [Vanlandschoot et al., 2002c]. As shown in Figure 4, a dose-dependent reduction of TNF- $\alpha$ secretion was observed when cells were stimulated with LPS in the presence of rHBsAg. However, using $50 \mu \mathrm{g} / \mathrm{ml}$ of rHBsAg, this reduction was twofold only for HEF002 and HEP715, while a 20 -fold reduction was obtained using DVP93/1.

\section{Enhanced Immune Recognition of HEP715 by PBMCs from High-Responder Hepatitis B Vaccinees}

The observation of differences in binding among rHBsAg preparations, despite the fact that all were derived from the same yeast species, was rather unexpected. The observation that reduced binding could be correlated with reduced inhibition of LPS-induced activation of monocytes raised the idea that the immune-suppressive attachment to monocytes might influence the HBsAg-specific T-cell proliferation. If this assumption was correct, an enhanced proliferation was predicted when using the low binding $\mathrm{rHBsAg}$ preparations.

The proliferative response of HBsAg-specific $\mathrm{T}$ cells toward the three rHBsAg preparations was investi- 

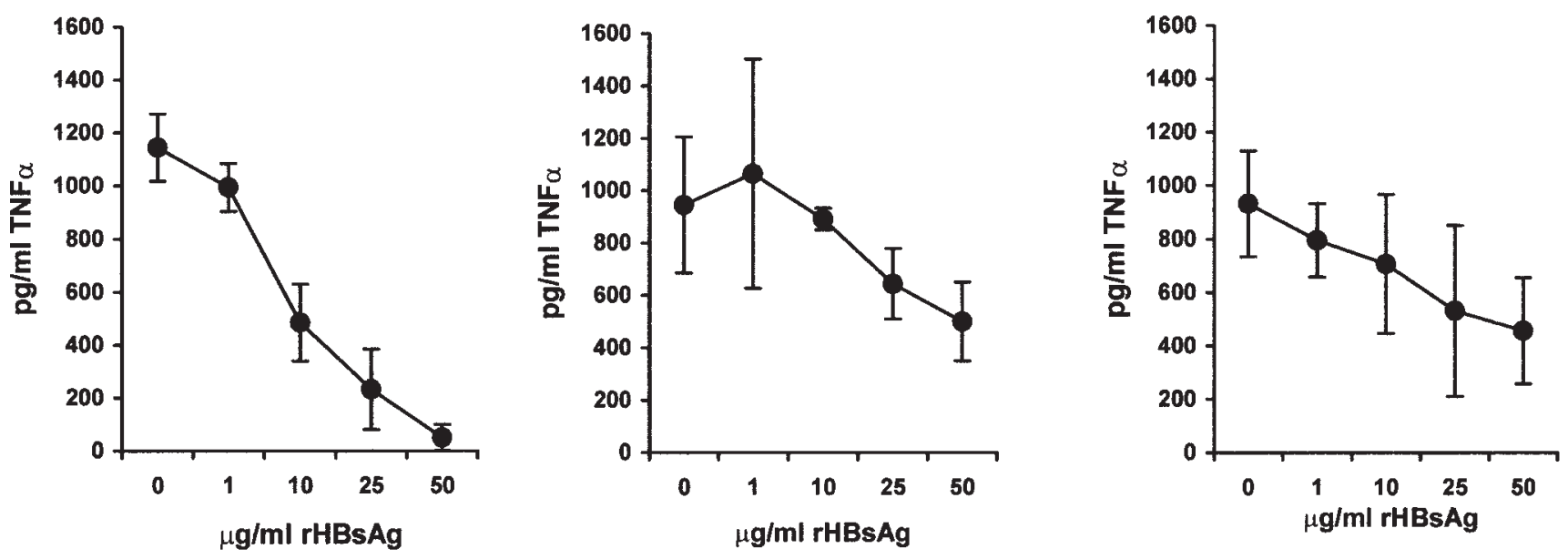

Fig. 4. Reduced inhibition of lipopolysaccharide (LPS)-induced secretion of tumor necrosis factor- $\alpha$ (TNF- $\alpha$ ) by HEF002 and HEP715; $3 \times 10^{5}$ 1,25-dihydroxy vitamin D3 differentiated THP-1 cells were incubated with $10 \mathrm{ng} / \mathrm{ml}$ LPS and different concentrations of DVP93/1 (left), HEF002 (middle), and HEP715 (right). Cell supernatant was collected after $4 \mathrm{hr}$ and cytokine concentrations determined. The data represent the mean of three separate experiments. Error bars represent SD.

gated, using unfractionated PBMCs from rHBsAg vaccinees (two high and two nonresponders) and two chronically infected patients. Increasing doses of rHBsAg were added to $2 \times 10^{5}$ PBMCs. rHBsAg-specific proliferation was not observed for PBMCs derived from nonresponders vaccinees and chronically infected patients (Fig. 5). PBMCs from all donors, except patient, proliferated when challenged with tetanus toxoid. This demonstrates that the lack of a response is specific for rHBsAg. HEP715 caused a significant higher proliferation (two- to fourfold) with PBMCs derived from the two different high responders, compared with the proliferation observed with DVP93/1.

\section{DVP93/1, HEF002, and HEP715 Contain Similar Amounts of Phosphatidylinositol}

Previously, it was reported that charged phospholipids determine whether binding of HBsAg to monocytes occur [Vanlandschoot et al., 2002b]. Because of the differences in attachment observed among DVP93/1, HEF002, and HEP715, it was expected to find differences in phospholipid content. However, as shown in Table I, the phospholipid content of DVP93/1, HEF002, and HEP715 was almost completely identical.

\section{DISCUSSION}

Since 1986, millions of doses of vaccines containing the $S$. cerevisiae-derived HBsAg have been administered. These vaccines are safe and immunogenic and have reduced the occurrence of hepatitis $B$ infections in the targeted populations [Leroux-Roels et al., 2001]. HBsAg, purified from plasma, contains the three viral membrane proteins, which are partially glycosylated. Compared with the natural HBsAg, this yeast-derived HBsAg only contains the S protein, which is nonglycosylated. Another known difference, which attracted little attention, is the presence of phosphatidylinositol in the yeast-expressed HBsAg. This phospholipid is absent in the natural HBsAg particles. The phospholipids of $S$. cerevisiae-derived $\mathrm{HBsAg}$ have also been shown to contain much more smaller $(\mathrm{C} 16 / \mathrm{C} 18=1.759)$ fatty acids compared with the natural HBsAg (C16/ $\mathrm{C} 18=0.484)$. In addition, $S$. cerevisiae-derived $\mathrm{HBsAg}$ contains more unsaturated fatty acids. As a result, the fluidity of $S$. cerevisiae-derived HBsAg lipid content is higher [Gavilanes et al., 1982; Van der Meeren et al., 1994]. The possible consequences of these differences in the lipid content and lipid structure have hardly been studied. Recent observations nevertheless demonstrate that such differences have unexpected consequences: $S$. cerevisiae-derived $\mathrm{HBsAg}$, and not plasma-derived HBsAg, was shown to bind to monocytes through interaction with the LPS binding protein and CD14. Upon detergent removal of the lipids and reconstitution of the proteins with charged phospholipids like phosphatidylserine and phosphatidylglycerol, binding of natural HBsAg was observed [Vanlandschoot et al., 2002b]. Because phosphatidylinositol is the only charged phospholipid found in Saccharomyces-expressed HBsAg [Van der Meeren et al., 1994; also data presented above], it was proposed that this lipid determines the interaction of rHBsAg with monocytes.

Initially, the purpose of the present study was to compare binding of HBsAg expressed in different yeast species ( $S$. cerevisiae and $H$. polymorpha) and mammalian cells with monocytes and to investigate their immune-suppressive potential. The lipid content of HBsAg expressed in these hosts is indeed variable [Van der Meeren et al., 1994; Diminsky et al., 1997]. However, obtaining vaccine HBsAg for this research purpose was difficult. The study was therefore limited to the use of three different lots of $S$. cerevisiaeexpressed rHBsAg, obtained from GlaxoSmithKline. Surprisingly, the results of two different binding assays 

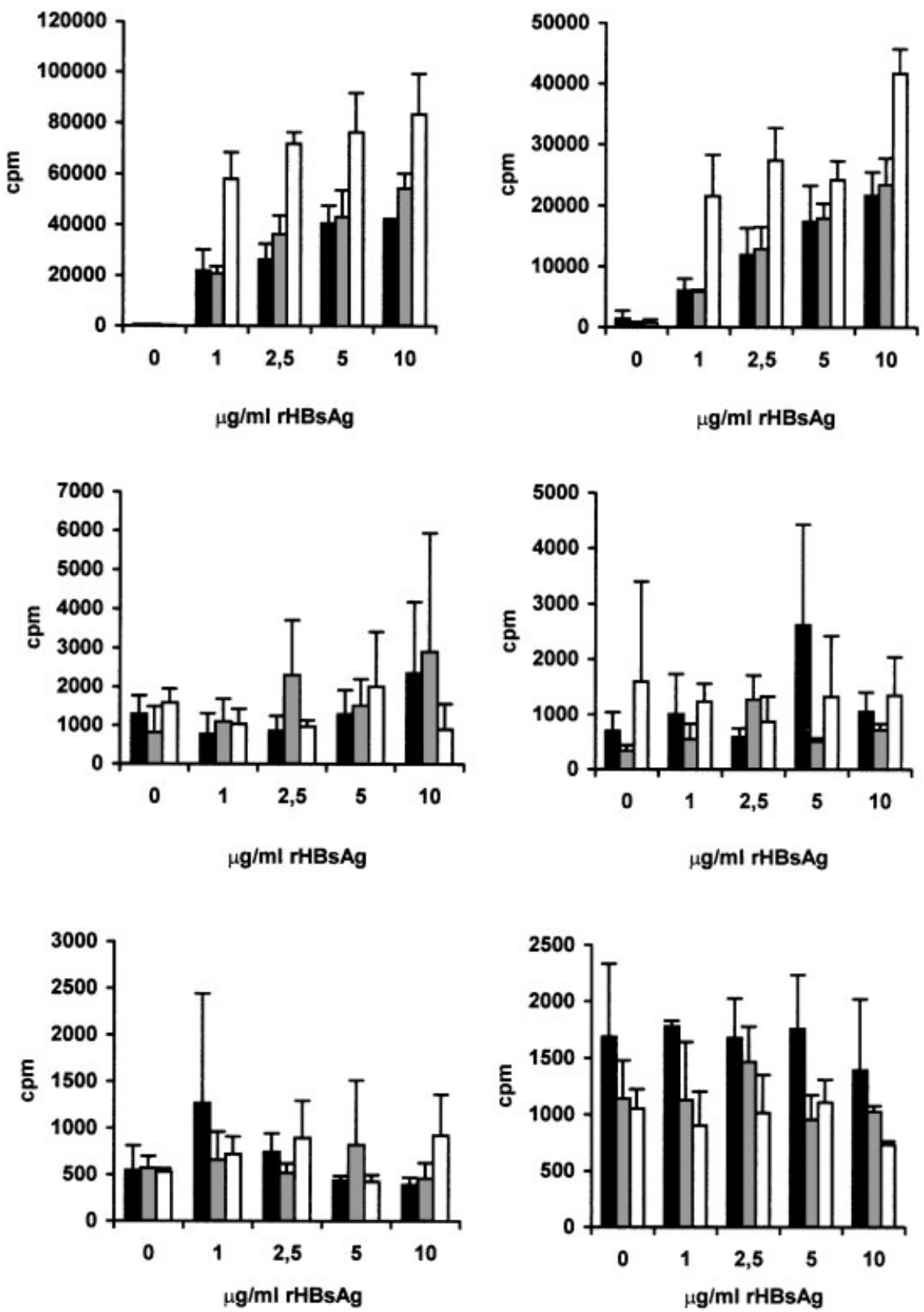

Fig. 5. Increased T-cell recognition of HEP715 by hepatitis B high-responder vaccinees. Increasing doses of DVP93/1 (black bars), HEF002 (gray bars) and HEP715 (white bars) were added to $2 \times 10^{5}$ unfractionated PBMCs of 2 Hepatitis B high-responder vaccinees (upper panels), 2 non-responder vaccinees (middle panels) and 2 chronically infected patients (lower panels). Lymphoproliferation was measured after 6 days of culture. Data show the mean of three wells. Error bars represent SD.

TABLE I. Phospholipid Content of DVP93/1, HEF002, and HEP715

\begin{tabular}{|c|c|c|c|c|c|c|c|c|c|}
\hline & \multicolumn{3}{|c|}{ DVP93/1 } & \multicolumn{3}{|c|}{ HEF002 } & \multicolumn{3}{|c|}{ HEP715 } \\
\hline & ng & $\mathrm{ng} / \mu \mathrm{g}$ & $\%$ & ng & $\mathrm{ng} / \mu \mathrm{g}$ & $\%$ & ng & $\mathrm{ng} / \mu \mathrm{g}$ & $\%$ \\
\hline Lyso PC & 24 & 4.8 & 1.4 & 16 & 2.9 & 0.9 & 35 & 4.5 & 1.4 \\
\hline $\mathrm{PC}$ & 1,038 & 207.6 & 60.8 & 1,005 & 183.4 & 57.7 & 1,377 & 176.3 & 54.6 \\
\hline PI & 543 & 108.6 & 31.8 & 589 & 107.5 & 33.8 & 889 & 113.8 & 35.2 \\
\hline $\mathrm{PE}$ & 101 & 20.2 & 5.9 & 132 & 24.1 & 7.6 & 222 & 28.4 & 8.8 \\
\hline
\end{tabular}


demonstrated clearly the reduced capacity of two rHBsAg preparations to bind to the cell surface of CD14-expressing cells. This reduced binding correlated with a 10-fold lower inhibition of LPS-induced secretion of TNF- $\alpha$ by THP-1 cells. When the T-cell immunogenicity was examined, a two- to fourfold higher proliferation was obtained, only with HEP715. This enhanced T-cell recognition was observed with PBMCs from high-responder vaccinees. Taken together, these results suggest a possible correlation between the capacity of rHBsAg to bind to monocytes and the potential to interfere with the normal function of monocytes.

The most likely explanation for the differences in binding observed among the three $\mathrm{rHBsAg}$ preparations was a difference in the phosphatidylinositol content of the particles. However, phospholipid content, and especially the amount of the charged phosphatidylinositol, was nearly identical. Although phospholipid content determines whether $\mathrm{HBsAg}$ particles can bind to monocytes, the possibility that a defined region of the $\mathrm{S}$ protein is involved in the interaction cannot be excluded [Vanlandschoot et al., 2002b]. Therefore, minor differences in folding among the three rHBsAg preparations might perhaps affect binding. Such rearrangements may be the consequence of the different properties of the yeast cells used for $\mathrm{rHBsAg}$ production, different purification methods, or storage conditions. However, all preparations were produced with the same stable transformed yeast strain, ruling out different host properties. DVP93/1 was stored for some time at $-20^{\circ} \mathrm{C}$ before putting it at $-70^{\circ} \mathrm{C}$. HEF002 and HEP715 were stored at $-70^{\circ} \mathrm{C}$. It is doubtful that this incubation at $-20^{\circ} \mathrm{C}$ is responsible for the high binding capacity of DVP93/1, because other recent rHBsAg preparations, all stored at $-70^{\circ} \mathrm{C}$, showed either high or low binding (data not shown). The possibility that different purification conditions are an underlying determinant is currently under investigation.

Although what causes the differences in binding to CD14 positive cells is unclear, a correlation between binding capacity and immunosuppression is suggested. Whether the suppressive interaction of yeast-expressed HBsAg with monocytes affects the anti-HBs levels after immunization with pure $\mathrm{rHBsAg}$, and whether this immunosuppressive effect is retained after adsorption of $\mathrm{rHBsAg}$ onto aluminum hydroxide, remains to be determined.

\section{ACKNOWLEDGMENTS}

The authors are indebted to GlaxoSmithKline for the recombinant yeast-derived $\mathrm{HBsAg}$ preparations. The authors thank Lia Sillekens for the generous gift of MAb F47B.

\section{REFERENCES}

Bligh EG, Dyer WJ. 1959. A rapid method of total lipid extraction and purification. Can J Biochem Physiol 235:911-917.

Diminsky D, Schrimbeck R, Reimann J, Barenholz Y. 1997. Comparison between hepatitis B surface antigen ( $\mathrm{HBsAg}$ ) particles derived from mammalian cells (CHO) and yeast cells (Hansuela polymorpha): composition, structure and immunogenicity. Vaccine 15:637-647.

Gavilanes F, Gonzales-Ros JM, Peterson DL. 1982. Structure of hepatitis B surface antigen. Characterization of the lipid components and their association with the viral proteins. J Biol Chem 257:7770-7777.

Jack RS, Grunwald U, Stelter F, Workalemahu G, Schutt C. 1995. Both membrane-bound and soluble forms of CD14 bind to gram-negative bacteria. Eur J Biochem 25:1436-1441.

Leroux-Roels G, Cao T, De Knibber A, Meuleman P, Roobrouck A, Farhoudi A, Vanlandschoot P, Desombere I. 2001. Prevention of hepatitis B infections: vaccination and its limitation. Acta Clin Belg 56:209-219.

Seeger C, Mason WS. 2000. Hepatitis B virus biology. Microbiol Mol Biol Rev 64:51-68.

Stelter F, Bernheiden M, Menzel R, Jack RS, Witt S, Fan X, Pfister M, Schutt C. 1997. Mutation of amino acids 39-44 of human CD14 abrogates binding of lipopolysaccharide and Escherichia coli. Eur J Biochem 243:100-109.

Stelter F, Loppnow H, Menzel R, Grunwald U, Bernheiden M, Jack RS, Ulmer AJ, Schutt C. 1999. Differential impact of substitution of amino acids 9-13 and 91-101 of human CD14 on soluble CD14dependent activation of cells by lipopolysaccharide. J Immunol 163:6035-6044.

Van der Meeren P, Van Criekinge W, Vanderdeelen J, Baert L. 1994. Phospholipid composition of r-DNA hepatitis B surface antigens. Int J Pharm 106:89-92.

Vanlandschoot P, Van Houtte F, Roobrouck A, Farhoudi A, LerouxRoels G. 2002a. Yeast derived hepatitis B surface antigen suppresses the activation of monocytes through interaction with a serum protein and a monocyte-specific receptor. J Gen Virol 83:1281-1289.

Vanlandschoot P, Van Houtte F, Roobrouck A, Farhoudi A, Stelter F, Peterson DL, Gomez-Gutierrez J, Gavilanes F, Leroux-Roels G. $2002 \mathrm{~b}$. LPS binding protein and CD14-dependent attachment of hepatitis B surface antigen to monocytes is determined by the phospholipid moiety of the particles. J Gen Virol 83:22792289.

Vanlandschoot P, Roobrouck A, Van Houtte F, Leroux-Roels G. 2002c. Recombinant HBsAg, an apoptotic-like lipoprotein, interferes with the LPS-induced phosphorylation of ERK-1/2 and JNK-1/2 in monocytes. Biochem Biophys Res Commun 297:486-491.

Weerheim AM, Kolb AM, Sturk A, Nieuwland R. 2002. Phospholipid composition of cell-derived microparticles determined by onedimensional high-performance thin-layer chromatography. Anal Biochem 302:191-198. 